\title{
EFFICACY OF FRUIT PULP SOLVENT EXTRACTS OF CASSIA FISTULA LINN. AGAINST THE FOURTH INSTAR LARVAE OF THE MOSQUITO CULEX QUINQUEFASCIATUS SAY
}

\author{
HUMAYUN REZA KHAN, TAIYEBA TANJINA, \\ JINIFATH-IR-RAHMAN AND HUMAYERA AFIA \\ Department of Zoology, University of Dhaka, Dhaka-1000, Bangladesh
}

\begin{abstract}
The efficacy of the fruit pulp extracts of Cassia fistula Linn (Caesalpiniodae: Leguminosae) extracted with three solvents (viz. water, acetone and n- hexanes) was studied against the $4^{\text {th }}$ instar larvae of Culex quinquefasciatus Say (Diptera: Culicidae) in the laboratory. Larval mortality was observed after 36 hours. The sun-dried extracts showed $18.67,30.67,41.33,54.67$ and 70.67 percent larval mortalities, respectively while the shade-dried extracts showed $6.67,21.33,42.67,68.00$ and 90.67 percent larval mortalities, respectively. The acetone based sun five extracts showed 18.67, 41.33, $60.00,82.67$ and 98.67 percent larval mortalities, respectively and the shade-dried extracts showed $17.33,41.33,73.33,89.33$ and 97.33 percent larval mortalities, respectively. The n-hexane based sun-dried extracts showed 21.33, 41.33, 59.67, 74.67 and 93.33 larval mortalities, respectively and the shade-dried extracts showed 33.33, $60.00,68.00,77.33$ and 97.33 percent larval mortalities, respectively. The $\mathrm{LC}_{50}$ values for n-hexane, acetone and water based sun-dried extracts were 1.087, 1.097 and 3.211 $\mathrm{mg} / \mathrm{ml}$, respectively and the shade-dried extracts were $0.808,1.054$ and $3.048 \mathrm{mg} / \mathrm{ml}$, respectively. No mortality was observed in control treatment.
\end{abstract}

Key words: Toxicity, Culex quinquefasciatus, Cassia fistula, Mosquito, Larvae, $\mathrm{LC}_{50}$

\section{Introduction}

Mosquitoes are dominant insects of tropical areas causing a great concern for the public health and are common nuisance pests throughout the urban areas of all over the world. There are over 3500 species of mosquitoes on the globe under 41 genera (Leisnham 2007). There are about 117 species of mosquitoes recorded in Bangladesh (Ahmed et al. 2009). So far 79 Culicines and 36 Anophelines have been recorded (Bashar et al. 2013) of which about 25 species are under the genus Culex, most common and predominant one being the species Culex quinquefasciatus (Ahmed 1987). In Dhaka city more than 90 per cent of the mosquitoes belong to Cx. quinquefasciatus (Ameen et al. 1994). Recently, (Khan et al. 2014 and 2015) reported 13 species of mosquitoes in five wards of Dhaka metropolitan city of which $C x$. quinquefasciatus was the predominant one.

The mosquitoes serve as vectors in the transmission of important pathogens to mankind that cause fatal diseases. About 300 species of mosquitoes are responsible for the transmission of the human and animal diseases. They transmit the pathogens of malaria, filaria, yellow fever, dengue fever, dengue hemorrhagic fever, encephalitis, dermatobiasis etc. Among them Culex mosquitoes carry encephalitis, filariasis, and the West Nile virus etc. Mosquito borne diseases attack about100 million people per year and more than one million of them die (Hill 1997). 
That's why the mosquitoes create global health problem, particularly in the tropics (WHO 1999). So, the mosquito Cx. quinquefasciatus is a serious threat to the human health. As its population is increasing in an alarming rate it requires to be controlled.

Now-a-days synthetic pyrithroid, carbamate, hydrochlorine and other organophosphorus compounds are used to control mosquitoes. These are harmful to human health and to other non-target populations because of their non biodegradable nature and higher rate of biological magnification through ecosystem. So, an alternative way should be found out which will be effective in the mosquito management strategies, along with it will focus on public health, monitoring and surveillance, source reduction and environmentally least-toxic larval control. These factors have resulted in an approach to look for environment friendly, cost-effective, biodegradable and target specific insecticides against mosquito species. Plant materials used as potential pesticides were first time studied in the country by Ameen et al. (1983a \& b and 1985). They studied the solvent based root extracts of Derris elliptica plant on the larvae of two mosquito species of the genera Aedes and Culex; they also isolated rotenone, the principal toxicant ingredient of $D$. elliptica and the chemical was bioassayed as insecticide on the larvae of the mosquito species. The plant Cassia fistula is a semi wild slender tree. It is known as "Golden Shower Tree" or "Sonalu" which is well known in Bangladesh as an ornamental tree for its beautiful bunches of yellow flowers. This plant is also well known for its traditional use as medicine. There is little information regarding the use of $C$. fistula as the source of insecticides and application to mosquito control in the country. However some information are available in literature in which different parts of $C$. fistula have been reported to be used as crude extracts with solvents as well as individual toxic ingredients for the control of different species of mosquitoes and other insect species (Govindarajan et al. 2008, Govindarajan 2009, 2013 a \& 2013 b, Barakat et al. 2004, Danish et al. 2011, Duraipandiyan et al.2011, Kumar et al. 2014, and Misra et al. 1997). The chemical components of $C$. fistula vary with in different parts of the plant. The pulp of pod of $C$. fistula contains anthraquinone glycosides, sennosides A and B, rhein and its glucoside, barbaloin, aloin, formic acid, butyric acid and their ethyl esters, oxalic acid, pectin, tannin, emodin, sennidin, aloe-emodin (Agarwal and Paridhavi 2005, Dave and ledwani 2012, Liptak and Szentagali 1937 and Misra et al. 1997). Some of these chemicals have larvicidal properties among which rhein was found to be a very effective larvicide (Duraipandiyan et al. 2011). Ethanol and hexane crude extracts of $C$. fistula reduce pupation, egg production, hatchability and increased per cent sterility in the cotton leaf worm, Spodoptera littoralis (Barakat et al.2004). Stearic acid has larvicidal properties and methanolic extracts of C. fistula are promising as larvicidal and ovicidal agents against mosquito (Danish et al. 2011).

The present study was conducted in the laboratory to determine the efficacy of three solvent based extracts of the fruit pulp of the plant Cassia fistula on the mosquito larvae of $C x$. quinquefasciatus.

\section{Materials and Methods}

Test insect: The larvae of the mosquito Cx. quinquefasciatus Say (Diptera: Culicidae) were collected from the drains of Curzon Hall premises, Dhaka University in October 2015 and were carried to the Entomological Laboratory of the Zoology department, Dhaka University where these were reared and bioassay tests were conducted in the ambient environment of the laboratory at $27 \pm 2^{\circ} \mathrm{C}$ and $75-85 \% \mathrm{RH}$. The larvae belonging to Cx. quinquefasciatus were identified by following the identifying key suggested by Bram (1967). 
As the larvae of $C x$. quinquefasciatus were required for the bioassay test with the plant extracts, a continuous supply of the larvae was maintained in the rearing room placed in the Animal Garden of the Department of Zoology, Dhaka University. The larvae were served with yeast powder, while the adults were provided with $10 \%$ glucose solutions as their food. After 3-4 days of emergence, the adult female mosquitoes were given a blood meal from a pigeon, Columba livia for egg maturation.

Test botanical: The fruits of the plant $C$. fistula were collected from the Curzon Hall campus area, Dhaka University and "Osmani Milonayoton" premises, Dhaka in November 2015 and carried to the Entomology laboratory. The extraction procedure was conducted at the Entomological laboratory of the Department of Zoology and CARS (Centre for Advanced Research Science) of the University of Dhaka. The collected plant parts were taken to the Botany Department of the University for the Species Identification and the species was confirmed as Cassia fistula.

Plant extraction: The fruits of C. fistula were collected and washed with tap water. Then one half of the collected materials was placed under the sun and the other half in the shade for drying. After drying, the shade-dried sample was found slightly sticky in comparison to the sun-dried sample. Then, the fruit pulps, excepting seeds and outer covering, were taken into an electric blender machine and ground into powder and stored.

Six conical flasks $(500 \mathrm{ml})$ were taken and rinsed with respective solvents for the preparation of different solvent based extract solutions. Then, $50 \mathrm{~g}$ of sun and $50 \mathrm{~g}$ of shade-dried fruit pulp powders of $C$. fistula were taken separately in each of the six flasks (three for sun-dried and three for shade dried extracts). With these $300 \mathrm{ml}$ fresh distilled water, Acetone, and nHexane were added separately and kept for 24 hours with periodic shaking in an Orbital Shaker Machine at $100 \mathrm{rpm}$ and $30^{\circ} \mathrm{C}$. The solutions were then collected and stored at temperature $4^{0} \mathrm{C}$ in an air tight glass bottle for dose preparation in bioassay tests.

Dose preparation: Several doses of the extracts were prepared for the experiment using a process of serial dilution. The plant extracts were taken into a screw capped vial and then weighed in a weighing machine. As the organic solvents based extracts were insoluble in water media, Di-methyl Sulfoxide (DMSO) was used to make them soluble in water as per the suggestion of Nour et al. (2012). The concentrations of the five doses for water based extracts were $2.0,2.5,3.0,3.5$ and $4.0 \mathrm{mg} / \mathrm{ml}$, and for acetone based extracts were $0.5,1.0$, $1.5,2.0$ and $2.5 \mathrm{mg} / \mathrm{ml}$. But, in case of $\mathrm{n}$-hexane solvent based extract, which was insoluble in DMSO solutions, were prepared by following the method proposed by Ravichandran et al. (2014). To prepare the stock solution, one gram of plant extract residue was dissolved in 5 $\mathrm{ml}$ of acetone, mixed well and then it was dissolved in $95 \mathrm{ml}$ of distilled water. Each $\mathrm{ml}$ of this stock solution contains $10 \mathrm{mg}$ of plant residue. By diluting this stock solution, a series of doses of different concentrations were prepared for bioassay tests and the concentrations of the prepared doses were $0.5,1.0,1.5,2.0$ and $2.5 \mathrm{mg} / \mathrm{ml}$.

Bioassay tests: A larviciadal bioassay method, suggested by Dua et al. (2009) was followed. The method was conducted with slight modification. Twenty five actively swimming mosquito larvae of $4^{\text {th }}$ instar, were taken into a conical flask $(250 \mathrm{ml})$ containing $100 \mathrm{ml}$ water along with one of the five doses of the plant extracts. The flasks were stored at room $29 \pm$ $2{ }^{\circ} \mathrm{C}, 80 \pm 5 \% \mathrm{RH}$ and at $14 \mathrm{~L}: 10 \mathrm{D}$ (photoperiod). The mortality of the larvae was recorded after 36 hours of exposures and the moribund larvae were counted as dead. A set of Control using 2.0\% DMSO was taken as control 1, a set of Control using 5\% Acetone was taken as 
control 2 and an untreated set of larvae in water (tap) as Control 3. These three sets of control were run for calculating the corrected mortality.

The toxicity of the extracts was calculated as $\mathrm{LC}_{50}$ and $\mathrm{LC}_{90}$ representing the $50 \%$ and $90 \%$ of the test larvae died, respectively; both $\mathrm{LC}_{50}$ and $\mathrm{LC}_{90}$ values were calculated for 36 hours of exposures. The number of larvae died at each of the dose concentrations at the end of the stipulated exposure periods was recorded and the mortality percentage values were calculated by using the formula-

$$
\begin{aligned}
& \text { Řn LC 牛 A 狞 C 懦狞 LǴRLǴ } \\
& \text { Percentage of mortality }=\ldots 100 \\
& \text { Řn LC 牛 SL 虐 SA 狞 C 懦狞 L }
\end{aligned}
$$

When the mortality in control was more than $5 \%$, the percentage mortality was corrected by using Abbott's (1925) formula-

$$
\begin{aligned}
& \text { 捻狞 C 懦狞 ACS 狞 ARS 哦 RaSCL 狞 SLaS-捻狞 C 懦狞 ACS 狞 ARS 哦 } \\
& \text { Ra } 7 \text { aSCA }
\end{aligned}
$$

Corrected mortality $=$ $\times 100$

400- 犭aSCACS 狞 ARS 哦

Statistical analysis: Larval mortality data were observed and corrected mortality was obtained by applying Abbott's formula (Abbott 1925). $\mathrm{LC}_{50}$ and $\mathrm{LC}_{90}$ at $95 \%$ confidence intervals, lower and upper confidence limits were determined by the probit analysis method suggested by Finney (1971). Other statistics like chi-square values, regression at 95\% confidence intervals of upper confidence limits and lower confidence limits and ttests were calculated using the IBM SPSS statistics 20 (Statistical Package of Social Science) software; here significance level were set at $\mathrm{p}<0.05$.

\section{Results and Discussion}

The larvicidal efficacy of different solvent based sun-dried and shade-dried extracts of the fruit pulp of $C$. fistula was tested against the $4^{\text {th }}$ instar larvae of $C x$. quinquefasciatus. Data were recorded and mean percentage mortality was calculated. Five different dose concentrations (viz. 2.0, 2.5, 3.0, 3.5 and $4.0 \mathrm{mg} / \mathrm{ml}$ ) of water based sun-dried extracts showed $18.67,30.67,41.33,54.67$ and $70.67 \%$ larval mortality, respectively; while the shade-dried extracts showed $6.67,21.33,42.67,68.00$ and $90.67 \%$ larval mortality, respectively. Five different dose concentrations (viz. 0.5, 1.0, 1.5, 2.0 and $2.5 \mathrm{mg} / \mathrm{ml}$ ) of acetone based sun-dried extracts showed 18.67, 41.33, 60.00, 82.67 and 98.67\% larval mortality, respectively; the shade-dried extracts showed 17.33, 41.33, 73.33, 89.33 and 97.33\% larval mortality, respectively. And five different dose concentrations (viz. 0.5,

$1.0,1.5,2.0$ and $2.5 \mathrm{mg} / \mathrm{ml}$ ) of n-hexane based sun-dried extracts showed 21.33, 41.33, $59.67,74.67$ and $93.33 \%$ larval mortality, respectively and the shade-dried extracts showed $33.33,60.00,68.00,77.33$ and $97.33 \%$ larval mortality, respectively. Based on the above larval mortalities, values of $\mathrm{LC}_{50}, \mathrm{LC}_{90}$, Chi-square, parameter estimation and $95 \%$ confidence limits were calculated and the results are presented in Table 1.

Table 1. Efficacy of different solvent based sun-dried and shade-dried extracts of the fruit pulp of Cassia fistula against the $4^{\text {th }}$ instar larvae of Cx. quinquefasciatus. 


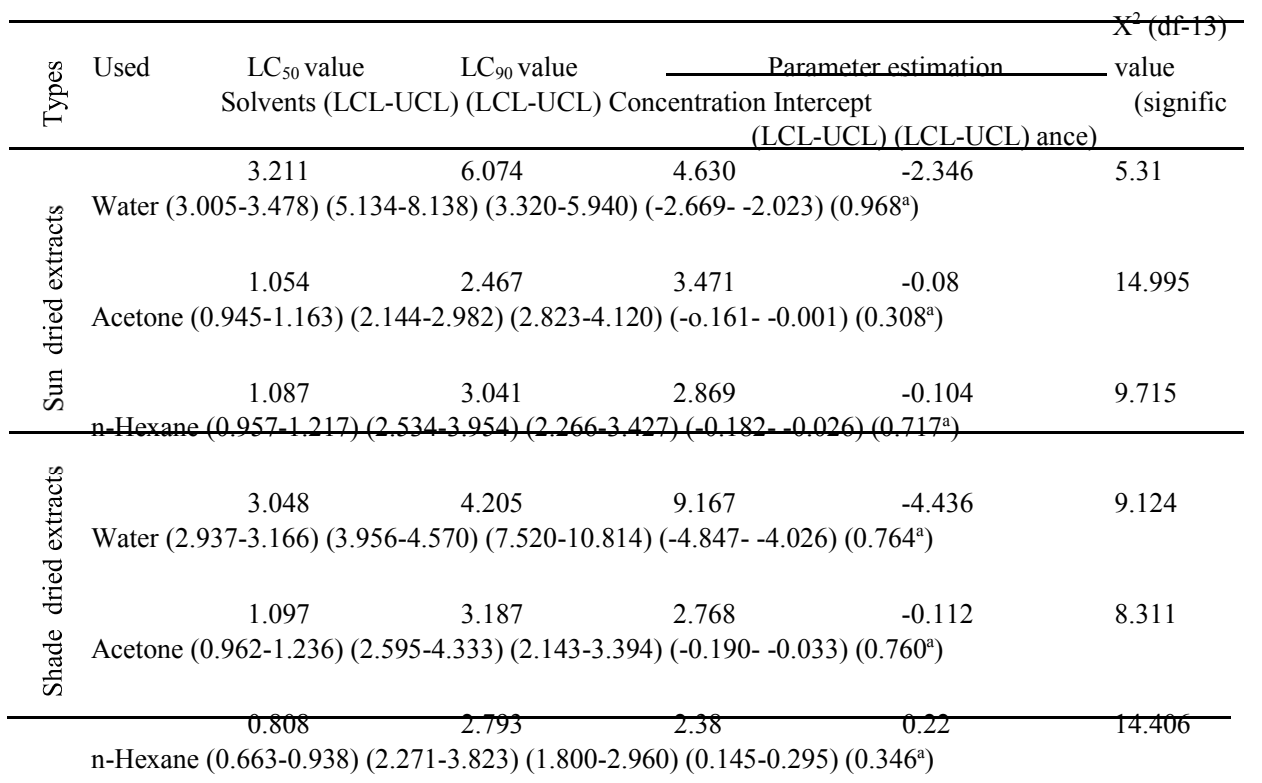

Here, $\mathrm{LC}=$ Lethal concentration, $\mathrm{LCL}=$ Lower confidence limit and $\mathrm{UCL}=$ Upper confidence limit of $95 \%$ confidence limits; $d f=$ Degree of freedom. $a=$ Since the significance level is greater than 0.15 , no heterogeneity factor is used in the calculation of confidence limits.

Comparison of the toxicity of different solvent based extracts of the sun-dried fruit pulp of $C$. fistula: The estimated $\mathrm{LC}_{50}$ for water, acetone and $\mathrm{n}$-hexane based sun-dried extracts were $3.211 \mathrm{mg} / \mathrm{ml}, 1.097 \mathrm{mg} / \mathrm{ml}$ and $1.087 \mathrm{mg} / \mathrm{ml}$, respectively; whereas LC 90 values of these extracts were $6.074 \mathrm{mg} / \mathrm{ml}, 2.467 \mathrm{mg} / \mathrm{ml}$ and $3.041 \mathrm{mg} / \mathrm{ml}$, respectively (Table 1). Here, the lowest $\mathrm{LC}_{50}$ and $\mathrm{LC}_{90}$ values belong to the $\mathrm{n}$-hexane based extracts and the highest of these values belong to the water based extracts. This indicates that among all these three, the n-hexane based extracts showed highest toxicity and the water based extract showed lowest toxicity; On the contrary the acetone based extracts showed larval toxicity laying in-between the former two extracts (i.e. n-hexane and water based extracts). The relative potency of three types of sun dried fruit extracts of $C$. fistula against the larvae of $C x$. quinquefasciatus on the basis of $\mathrm{LC}_{50}$ values in decreasing order were as follows: $\mathrm{n}$-hexane $(1.087 \mathrm{mg} / \mathrm{ml})>$ acetone $(1.097 \mathrm{mg} / \mathrm{ml})>$ water $(3.211 \mathrm{mg} / \mathrm{ml})$.

Comparison of the toxicity of different solvent based extracts of the shade-dried fruit pulp of $C$. fistula: The estimated $\mathrm{LC}_{50}$ for water, acetone and n-hexane based extracts were

$3.048,1.054$ and $0.808 \mathrm{mg} / \mathrm{ml}$, respectively; whereas, the $\mathrm{LC}_{90}$, values were $4.205,3.187$ and $2.793 \mathrm{mg} / \mathrm{ml}$, respectively (Table 1). Thus, the $\mathrm{n}$-hexen based extracts showed lowest $\mathrm{LC}_{50}$ and $\mathrm{LC}_{90}$ values and the water based extracts showed highest $\mathrm{LC}_{50}$ and $\mathrm{LC}_{90}$ values indicating that the shade-dried extracts showed the same results as that of the sun-dried extracts, i.e. among all these three, $n$-hexane based extract was highest in toxicity level and the water based extract was lowest and acetone based extract was moderate. The relative potency of three types of sun-dried fruit extracts of $C$. fistula against the $4^{\text {th }}$ instar larvae of Cx. quinquefasciatus, on the basis of $\mathrm{LC}_{50}$ values in decreasing order were as follows: $\mathrm{n}$ hexane $(0.808 \mathrm{mg} / \mathrm{ml})>$ acetone $(1.054 \mathrm{mg} / \mathrm{ml})>$ water $(3.048 \mathrm{mg} / \mathrm{ml})$. 
Comparison of toxicity between sun-dried and shade-dried fruit pulps of C. fistula: Among all six types of solvent extracts, the n-hexane based shade-dried extract was found to be most effective $\left(\mathrm{LC}_{50}=0.808 \mathrm{mg} / \mathrm{ml}\right)$ larvicide against the tested larvae of $C x$. quinquefasciatus; the acetone based sun-dried extract ranked $2^{\text {nd }}$ in position of toxicity $\left(\mathrm{LC}_{50}=1.054 \mathrm{mg} / \mathrm{ml}\right)$; with the $\mathrm{LC}_{50}$ values of the $\mathrm{n}$-hexane based sun-dried extract $\left(\mathrm{LC}_{50}=1.087 \mathrm{mg} / \mathrm{ml}\right)$ and acetone based sun-dried extract $\left(\mathrm{LC}_{50}=1.097 \mathrm{mg} / \mathrm{ml}\right)$ were in the $3^{\text {rd }}$ and $4^{\text {th }}$ position, respectively. The water based extracts were found to be less effective than the acetone and n-hexane based extracts and the $\mathrm{LC}_{50}$ values were $3.048 \mathrm{mg} / \mathrm{ml}$ and $3.211 \mathrm{mg} / \mathrm{ml}$ for shade-dried and sundried extract, respectively. The relative potency of six types of extracts on the basis of the decreasing order of $\mathrm{LC}_{50}$ values were as follows: n-hexane shade $(0.808 \mathrm{mg} / \mathrm{ml})>$ acetone shade $(1.054 \mathrm{mg} / \mathrm{ml})>$ n-hexane sun $(1.087 \mathrm{mg} / \mathrm{ml})>$ acetone sun $(1.097 \mathrm{mg} / \mathrm{ml})>$ water shade $(3.048 \mathrm{mg} / \mathrm{ml})>$ water sun $(3.211 \mathrm{mg} / \mathrm{ml})$. So, for the same solvent based extract, effectiveness of the shadedried extracts was found better than the sun-dried extracts.

Comparison between sun and shade-dried extracts: Paired t-test was performed to show the comparative results between sun-dried and shade-dried extracts at all three solvents (Table 2). The water based shade-dried and sun-dried extracts, acetone based sun-dried and shadedried extracts and n-hexane based sun-dried and the shade-dried extracts of the fruit pulp of C. fistula were found to be significant as shown in Table 2. The differences of the estimated means were 2.60, 1.2 and 2.8, respectively. The paired sample t-test values were 3.833, 1.39 and 4.221, respectively. And paired sample correlation values were 0.982, 9.74 and 9.83, respectively. As all the values were less than 0.005 , the results were significant.

Table 2. Differences between the larvicidal efficacy of different solvent based sun dried and shade dried extracts of the fruit pulp of C. fistula against the $4^{\text {th }}$ instar larvae of Culex quinquefasciatus.

\begin{tabular}{|c|c|c|c|c|c|c|c|c|c|}
\hline Solvents & Type & 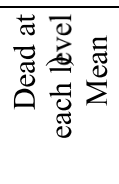 & 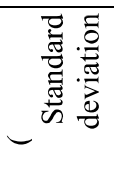 & 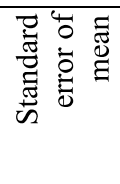 & 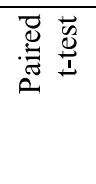 & 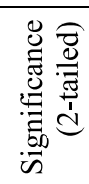 & 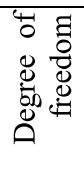 & 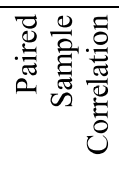 & 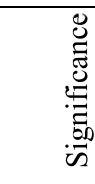 \\
\hline & Sun & 9.800 & 6.181 & 2.764 & & & & & \\
\hline Water & Shade & 12.40 & 7.057 & 3.156 & 3.833 & 0.019 & 4 & 0.982 & 0.003 \\
\hline & Sun & 14.60 & 7.603 & 3.400 & & & & & \\
\hline Acetone & Shade & 15.80 & 8.258 & 3.693 & 1.395 & 0.235 & 4 & 0.974 & 0.005 \\
\hline & Sun & 14.20 & 7.120 & 3.184 & & & & & \\
\hline n-Hexane & Shade & 17.00 & 6.285 & 2.811 & 4.221 & 0.013 & 4 & 0.983 & 0.003 \\
\hline
\end{tabular}

In the present study, the crude extracts of the fruit pulp of C. fistula were found to have effective larvicide against $C x$. quiquefasciatus. The resulting larvicidal activities of the fruit pulp extracts of $C$. fistula may be comparable with some of the earlier reports. Govindarajan et al. (2008) studied the ovicidal and larvicidal efficacy of methanolic leaf extracts of $C$. fistula against two mosquitoes, viz. Anopheles stephensi and Culex quinquefasciatus and reported the $\mathrm{LC}_{50}$ values of 17.95 and $20.57 \mathrm{mg} / \mathrm{L}(=0.02057 \mathrm{mg} / \mathrm{ml})$, respectively. Thus it seems that the methonolic extracts of the leaves of $C$. fistula are more toxic than all three solvent extracts of the fruit pulp of the same plant in the present study. Later Govindarajan 
(2013) studied the efficacy of crude methanolic extracts of the flower of $C$. fistula against three mosquito species, viz. Culex tritaeniorhynchus, Aedes albopictus and Anopheles subpitus, and reported that the flower extracts of $C$. fistula were excellent larvicidal potential against the tested mosquito species showing the $\mathrm{LC}_{50}$ values of $136.59,118.64$ and 96.51 ppm, respectively, and with the $\mathrm{LC}_{90}$ values of $243.67,231.79$ and $174.39 \mathrm{ppm}$, respectively. In another earlier study, Govindarajan et al. (2009) reported the bioefficacy of $C$. fistula leaf extracts with different solvents like benzene, acetone and methanol against dengue vector Aedes aegypti and estimated $\mathrm{LC}_{50}$ values of the above extracts which were 10.69, 18.27 and $23.95 \mathrm{mg} / \mathrm{L}$, respectively; these values indicate that the benzene leaf extracts of $C$. fistula had highest efficacy on the larvae of Ae. Aegypti.

Duraipandiyan et al. (2011) reported the antifeedant and larvicidal activities of the chemical rhein isolated from $C$. fistula and the $\mathrm{LC}_{50}$ value were $606.50 \mathrm{ppm}(0.607 \mathrm{mg} / \mathrm{ml})$ for Heliothis armigera and $1192.55 \mathrm{ppm}(1.193 \mathrm{mg} / \mathrm{ml})$ for Spodoptera littoralis and the larvae survived showed malformed adults. Kumar et al. (2014) reported the $\mathrm{LC}_{50}$ of Cassia occidentalis leaf petroleum ether and butanol extract against $C x$. quinquefasciatus $3^{\text {rd }}$ instar larvae were 98.4 and $161.6 \mu \mathrm{g} / \mathrm{ml}$, respectively. Barakat et al. (2004) reported that the ethanol and hexane crude extracts of Cassia fistula reduced pupation, egg production and hatchability, and increased per cent sterility; the dominant constituents were fatty acids, linoleic acid, hexadecanoic acid, and octadecanoic acid and their alkyl esters.

From the present findings and the relevant information available from literature it may be said that the plant $C$. fistula is a potential resource for the extraction of toxic ingredients which may be used as insecticides for the control of mosquito. Further research may be initiated to isolate the toxic ingredients from different plant parts of this species and biassayed on mosquito species.

\section{References}

Abbott, W.S. 1925. A method of computing the effectiveness of insecticides. J. Econ. Entomol. 18(2): 267-269.

Agarwal, S.S. and M. Paridhavi. 2005. Clinically useful herbal drugs. Ahuja Publishing House. 281-282 pp.

Ahmed, T.U. 1987. Checklist of mosquitoes of Bangladesh. Mosquito systematic. 19:191-204.

Ahmed, T.U., J. Nur and A.F. Naved. 2009. Mosquito populations, including new record, in the tea gardens of Bangladesh. Bangladesh J. Entomol. 19(2): 45-60.

Ameen, M., M.A. Chowdhury and I. Hossain. 1994. Survey of mosquito breeding site in the city of Dhaka: a report submitted to the Dhaka City Corporation, Dhaka. 77pp.

Ameen, M., R.M. Shahjahan, H.R. Khan and A.K.A. Chowdhury. 1985. Larvicidal effects of indigenous Derris elliptica root on Aedes aegypti (Diptera: Culicidae). Itern. Quart. Entomol. 1:39-43.

Ameen, M., A.K.A. Chowdhury. H.R. Khan and R.M. Shahjahan. 1983 a. Insecticidal properties of Derris elliptica (Wall.) (Leguminosae:Papilionaceae) roots against the larvae of Culex fatigans Wied. (Diptera: Culicidae). Dhaka Univ. Stud. B 31(1):1-11.

Ameen, M., R.M. Shahjahan., H.R. Khan, and A.K.A. Chowdhury. 1983 b. Toxicity of rotenone extracted from indigenous Derris roots on mosquito larvae. J. Bangladesh Acad. Sci. 7(1\&2):39-47.

Barakat, A.A., A.S. El-mahy, K. Omaima, K. Moustafa, F.A. Mansour and K.M. El-hadek. 2004. Biological effect of Cassia fistula (L.) seeds against the cotton leaf worm Spodoptera littoralis (Boisd.) with special reference to chemical constituents. Bull. Entomol. Soc. Egypt. Econ. 30: 1-14. 
Bashar, K., K.H. Mahmud, M.S. Reza, P. Goda, F.F. Rain, M. Jesmin and A. Asaduzzaman. 2013. Revised checklist and distribution maps of Anopheles (Insecta: Diptera: Culicidae: Anophelinae) mosquitoes of Bangladesh. J. Biodiv. Data. 9(2):211-224.

Bram, A.R. 1967. Contributions to the mosquito fauna of Southeast Asia-11. The genus Culex in Thailand (Diptera: Culicidae). Am. Ent. Inst. 2(1): 192-201.

Danish, M., P. Singh, G. Mishra, S. Srivastava, K.K. Jha and R.L. Khosa. 2011. Cassia fistula Linn. (Amulthus)- An Important Medicinal Plant: A Review of Its Traditional Uses, Phytochemistry and Pharmacological Properties. J. Nat. Prod. Plant Resour. 1(1): 101118.

Dave, H. and L. Ledwani. 2012. A review on enthraquinones isolated from Cassia species and their application. Indian J. Nat. Prod. Resour. 3(3): 291-319.

Dua, V.K., A.C. Pandey, K. Raghavendra, A. Gupta, T. Sharma and A.P. Dash. 2009. Larvicidal activity of neem oil (Azadirachta indica) formulations against mosquitoes. Malaria J. 8(1): 124 .

Duraipandiyan, V., S. Ignacimuthu and M.G. Paulraj. 2011. Antifeedant and larvicidal activities of Rhein isolated from the flowers of Cassia fistula L. Saudi J. Biol. Sci. 18(2): 129133.

Finney, D.J. 1971. Probit Analysis. Cambridge University press, London. 68-78 pp.

Govindarajan, M. 2013 a. Larvicidal activity of Cassia fistula flower against Culex tritaeniorhynchus Giles, Aedes albopictus Skuse and Anopheles subpitus Grassi (Diptera: Culicidae). J. Pure Appl. Zool. 1(2): 117-121.

Govindarajan, M. 2013 b. Bioefficacy of Cassia fistula Linn. (Leguminosae) leaf extract against chikungunya vector, Aedes aegypti (Diptera: Culicidae). Eur. Rev. Med. Pharmacol. Sci. 13: 99-103.

Govindarajan, M. 2009. Bioefficacy of Cassia fistula Linn. (Leguminosae) leaf extract against chikungunya vector, Aedes aegypti (Diptera: Culicidae). Eur. Rev. Med.Pharmacol. Sci. 13:99-103.

Govindarajan, M., A. Jebanesan and T. Pushpanathan. 2008. Larvicidal and ovicidal activities of Cassia fistula Linn. leaf extract against filarial and malarial vector mosquitoes. Parasitol. Res. 102: 289-292.

Hill, D.S. 1997. Economic importance of insects (1 $1^{\text {st }}$ ed.) Chapman and Hall, London. 83 pp.

Khan, H.R., M. Mujahid, T. Akter, M.R. Karim and M.S. Farid. 2014. Mosquito diversity in the Two wards of Dhaka city. Dhaka Univ. J. Biol. Sci. 23(1): 17-26.

Khan, H.R., T. Akter, M.S. Farid, M.M. Islam and M.R. Karim. 2015. Seasonal fluctuations of various mosquito species in two wards of Dhaka city. Physiol. Ecol. \& Environ. Sci. 5(1\& 2):51-58.

Kumar, D., R. Chawla, P. Dhamodaram. and N. Balakrishnan. 2014. Larvicidal Activity of Cassia occidentalis (Linn.) against the Larvae of Bancroftian Filariasis Vector Mosquito Culex quinquefasciatus. J. Parasitol. Res. 2014.

Leisnham, P.T., D.P. Slaney, P.J. Lester, P. Weinstein and A.C.G. Heath. 2007. Mosquito density, associated macro invertebrate biodiversity, and water chemistry in water filled containers: Relationships to land use. New Zealand J. Zool. 37:203-218.

Liptak, P. and I. Szentagali. 1937. A Cassia fistula hatóanyaga. Ber. Ungar. Pharm. Ges. 13: 61-63.

Misra, T.R., R.S. Singh, H.S. Pandey and B.K. Singh. 1997. A new diterpene from Cassia fistula pods. Fitoterapia. LXVIII(58):375.

Nour, A.H., J. Sandanasamy and A.H. Nour. 2012. Larvicidal activity of extracts from different parts of the Neem (Azadirachta indica) against Aedes aegypti mosquitoes' larvae. Sci. Res. Essays. 7(31): 2810-2815.

Ravichandran, R., D. Thandaraj and M. Alwarsamy. 2014. Antimosquito Activity of Leaf Extract of Neem (Melia azedarach) and Papaya (Corica papaya) detected against the larvae Culex quiquefasciatus. Int. J. Inno. Res. Sci. Eng. Tech. 3(4):11928-11935. 
WHO. 1999. Tropical Disease Research Progress 1997-1998. Fourteenth Programme Report. UNDP/World Bank/WHO Special Programme for Research and Training in tropical Disease (TDR), Geneva, Switzerland, TDR/PR14/FIL/199.1.26 pp.

(Revised copy received on 26/1/2017) 